\title{
Successful treatment of primary intracranial sarcoma with the ICE chemotherapy regimen and focal radiation in children
}

\author{
Lucie Lafay-Cousin, MD, ${ }^{1}$ Gillian Lindzon, MD, ${ }^{3}$ Michael D. Taylor, MD, PhD, ${ }^{5}$ Walter Hader, MD, ${ }^{2}$ \\ Cynthia Hawkins, MD, PhD, ${ }^{6}$ Robert Nordal, MD, ${ }^{8}$ Normand Laperriere, MD, ${ }^{9}$ \\ Suzanne Laughlin, MD, ${ }^{7}$ Eric Bouffet, MD, ${ }^{4}$ and Ute Bartels, MD ${ }^{4}$
}

\begin{abstract}
'Division of Pediatric Hematology, Oncology, and Bone Marrow Transplantation, and 2Division of Pediatric Neurosurgery, Alberta Children's Hospital, Calgary, Alberta; ${ }^{3}$ Division of Paediatrics, ${ }^{4}$ Division of Haematology/Oncology, Paediatric Brain Tumour Program, ${ }^{5}$ Division of Neurosurgery, ${ }^{6}$ Division of Neuropathology, and ${ }^{7}$ Division of Neuro-Radiology, The Hospital for Sick Children, Toronto, Ontario; ${ }^{8}$ Division of Radiation Oncology, Tom Baker Cancer Center, Calgary, Alberta; and ${ }^{9}$ Department of Radiation Oncology, Princess Margaret Hospital, Toronto, Ontario, Canada
\end{abstract}

\begin{abstract}
OBJECTIVE Primary CNS sarcomas are very rare pediatric tumors with no defined standard of care.
METHODS This study was a retrospective review of children diagnosed with a primary CNS sarcoma and treated at 2 Canadian tertiary care centers between 1995 and 2012. This report focuses on patients with cerebral hemispheric tumor location due to their specific clinical presentation.
\end{abstract}
RESULTS Fourteen patients with nonmetastatic primary CNS sarcoma were identified; in 9 patients, tumors were lo- cated in the cerebral hemisphere and 7 of these patients presented with intratumoral hemorrhage. One infant who died of progressive disease postoperatively before receiving any adjuvant therapy was not included in this study. The final cohort therefore included 8 patients (4 males). Median patient age at diagnosis was 11.8 years (range 5.8-17 years). All tumors were located in the right hemisphere. Duration of symptoms prior to diagnosis was very short with a median of 2 days (range 3-7 days), except for 1 patient. Three (37.5\%) patients had an underlying diagnosis of neurofibromatosis Type 1 (NF1). Gross-total resection was achieved in 5 patients. The dose of focal radiation therapy (RT) ranged between $54 \mathrm{~Gy}$ and $60 \mathrm{~Gy}$. Concomitant etoposide was administered during RT. ICE (ifosfamide, carboplatin, etoposide) chemo- therapy was administered prior to and after RT for a total of $6-8$ cycles. Seven of the 8 patients were alive at a median time of 4.9 years (range 1.9-17.9 years) after treatment.

CONCLUSIONS In this retrospective series, patients with primary CNS sarcomas located in the cerebral hemisphere most commonly presented with symptomatic acute intratumoral hemorrhage. Patients with NF1 were overrepresented. The combination of adjuvant ICE chemotherapy and focal RT provided encouraging outcomes.

http://thejns.org/doi/abs/10.3171/2015.6.PEDS14709

KEY WORDS adjuvant chemotherapy; brain tumor; CNS sarcoma; intracranial hemorrhage; oncology

$\mathrm{P}$ RIMARY CNS sarcomas are rare primitive mesenchymal, nonmeningothelial tumors accounting for less than $0.2 \%$ of intracranial lesions that may occur at any age and affect both sexes equally. ${ }^{9}$ Current knowledge about clinical presentation and best therapeutic management is limited by the restricted number of patients reported over a long period of time and treated with various modalities. In this report, we describe our experience with a series of consecutive patients treated uniformly with adjuvant focal radiation and chemotherapy and highlight the specific presentation of primary nonmetastatic CNS sarcomas located in the cerebral hemispheres.

\section{Methods}

\section{Study Population}

This retrospective series included children less than 18 years of age diagnosed and treated for a primary cerebral sarcoma at The Hospital for Sick Children in Toronto, Ontario, Canada, and the Alberta Children's Hospital in

ABBREVIATIONS GTR = gross total resection; ICE = ifosfamide, carboplatin, etoposide; $M C A=$ middle cerebral artery; MINST = malignant intracerebral nerve sheath tumor; NF1 = neurofibromatosis Type 1; OS = overall survival; PFS = progression-free survival; RT = radiation therapy; $S T R=$ subtotal resection.

SUBMITTED January 13, 2015. ACCEPTED June 30, 2015.

INCLUDE WHEN CITING Published online November 20, 2015; DOI: 10.3171/2015.6.PEDS14709. 
Calgary, Alberta, Canada, between November 1995 and November 2012.

Queries of the institutional pediatric neurooncology and pathology databases included the key words primary sarcoma, undifferentiated sarcoma, and sarcoma not otherwise specified. Information extracted from medical records comprised demographic data, presenting symptoms, staging investigations, surgical reports, pathology, and diagnostic imaging reports. The details of the chemotherapy protocol and radiation therapy (RT), along with outcome data, were also collected. Patients with metastatic disease were excluded. The ethics review boards of each institution approved this study.

Resection was evaluated according to the surgical report and the postoperative MRI report. Gross-total resection (GTR) accounted for no visible residual disease. Neartotal resection was defined by a resection greater than $90 \%$ and subtotal resection (STR) by a resection between 50\% and $90 \%$. Biopsy was defined as a resection of less than $10 \%$ of the mass. All remaining situations accounted for partial resection. Staging included MRI brain and spine, lumbar CSF, and bone scan/bone marrow aspirate. The primary CNS location of the sarcoma was confirmed by ruling out the presence of extra CNS tumor sites on CT scan or total body MRI, or both of these. Prior to the surgical procedure, depending on the patient's clinical situation, further workup, such as MR angiography or angiography, was attempted.

\section{Treatment Plan}

Following maximal safe resection, patients received ICE (ifosfamide, carboplatin, and etoposide) chemotherapy consisting of ifosfamide $3 \mathrm{~g} / \mathrm{m}^{2}$ intravenously over 3 hours on Day 1 and Day 2; etoposide $150 \mathrm{mg} / \mathrm{m}^{2}$ intravenously over 1 hour on Day 1 and Day 2, and carboplatin $500 \mathrm{mg} /$ $\mathrm{m}^{2} \mathrm{IV}$ over 2 hours on Day 3. A subsequent increased dose of carboplatin up to $600 \mathrm{mg} / \mathrm{m}^{2}$ was recommended based on hematological tolerance. Chemotherapy cycles were given every 21-28 days, depending on blood cell count recovery, and administered in a sandwich-type manner before and after focal radiation to the primary tumor site. Focal radiation was administered with concomitant oral etoposide ( $35 \mathrm{mg} / \mathrm{m}^{2}$ for 3 weeks, then 1 week off). This regimen was used at both institutions in the absence of a disease-specific protocol as a standard of care regimen.

\section{Statistical Analysis}

Data were analyzed using SPSS software (version 16.0, SPSS Inc.). The Kaplan-Meier method was used to estimate the probability of progression-free survival (PFS) and overall survival (OS). PFS was determined from the date of diagnosis to the date of disease progression or relapse. Overall survival was assessed from the date of last follow-up or the date of death from any cause.

\section{Results \\ Demographics}

From 1995 to 2012, 14 patients were consecutively diagnosed with a localized primary CNS sarcoma at 2 different Canadian pediatric institutions. Four tumors were located within the posterior fossa, 1 at the tentorium cere- belli with infra- and supratentorial extension, and 9 (64\%) in the cerebral hemispheres. Because the 5 patients with infratentorial and tentorium tumors received less homogenous treatment, did not have hemorrhagic presentation, and only 1 survived, they were not included in the current report.

Among the 9 patients with hemispheric lesions, 1 infant, who suffered a severe postoperative stroke, did not receive adjuvant therapy, and died of progressive disease within 6 weeks, and thus was excluded from this review. This study therefore focuses on the 8 patients ( 4 males) with hemispheric sarcoma who were amenable to adjuvant therapy, consisting of focal radiation with concomitant oral etoposide and ICE chemotherapy regimen.

The patients' characteristics are described in Table 1. The median age at diagnosis was 11.8 years (range 5.817.8). Three patients (37.5\%) had underlying neurofibromatosis Type 1 (NF1). All 8 tumors were located in the right hemisphere with an equal distribution between the temporal and frontal lobes. Metastatic workup was negative and confirmed the diagnosis of a nondisseminated primary CNS sarcoma in all patients.

\section{Presenting Symptoms}

Duration of symptoms prior to diagnosis was very short with a median of 2 days for all patients except 1 . Although this patient (Case 7) presented to the ER with acute onset of severe headaches and a decreased level of consciousness, he was undergoing neurological investigation for an isolated left leg numbness identified 6 weeks prior.

At the time of the diagnosis, all patients except 1 presented with clinical and radiographic evidence of intratumoral hemorrhage. Notably, 3 of these patients had previously experienced intracranial hemorrhage prior to their definitive diagnosis of primary intracranial sarcoma. One of them (Case 5) presented with a rupture of a right middle cerebral artery (MCA) aneurysm, while the 2 others (Cases 1 and 4) did not have a vascular malformation detected on postoperative angiography (Fig. 1). No obvious tumor mass was detected during the surgical exploration of the first hemorrhagic event. However, in Case 1, a small enhancing nodular lesion in the superior temporal gyrus described on MRI could not be explored upfront due to the hemodynamic instability of the patient during initial surgery. In these 3 patients, the tumor mass identified at the time of the second hemorrhagic episode was in the same location as the initial hemorrhage. The second hemorrhagic event in Cases 1, 4, and 5 occurred 17 days, 1 month, and 1 year, respectively, following the initial hemorrhage.

\section{Surgery}

All patients underwent at least 1 surgical procedure to evacuate the hematoma and remove the tumor with the aim of achieving maximal safe resection. GTR was achieved in 5 patients (62.5\%). A safe GTR was impossible in 2 patients (Cases 5 and 8) due to tumor involving MCA territory and substantial intraoperative bleeding and hypotension. One patient (Case 4) had a very small residual enhancing lesion within the surgical cavity on postoperative MRI. All except 1 tumor were described as intra-axial. 
TABLE 1. Patient characteristics

\begin{tabular}{|c|c|c|c|c|c|c|c|}
\hline $\begin{array}{l}\text { Case } \\
\text { No. }\end{array}$ & $\begin{array}{c}\text { Age at } \\
\text { Diagnosis } \\
\text { (yrs), Sex }\end{array}$ & $\begin{array}{l}\text { Underlying } \\
\text { NF1 }\end{array}$ & Tumor Location & Presenting Symptom (Days) & $\begin{array}{l}\text { Hemorrhagic Event at } \\
\text { Presentation }\end{array}$ & Histopathology* & $\begin{array}{c}\text { Vascular } \\
\text { Malformation } \\
\text { on Angiogram }\end{array}$ \\
\hline 1 & $14.5, \mathrm{M}$ & Present & Rt temporal lobe & HA, vomiting (2) & $\begin{array}{l}\text { Rt temporal hemor- } \\
\text { rhage } \times 2\end{array}$ & Leiomyosarcoma & Absent \\
\hline 2 & 7.7, M & Present & Rt temporal lobe & HA, vomiting, lethargy (2) & $\begin{array}{l}\text { Rt temporal hemor- } \\
\text { rhage }\end{array}$ & $\begin{array}{l}\text { Undifferentiated } \\
\text { sarcoma }\end{array}$ & Absent \\
\hline 3 & $6.5, \mathrm{~F}$ & Absent & Rt temporal lobe & $\begin{array}{l}\text { Acute onset N/V, decreased LOC, } \\
\text { It hemiparesis }(<1)\end{array}$ & $\begin{array}{l}\text { Rt temporal thalamic } \\
\text { hemorrhage }\end{array}$ & $\begin{array}{l}\text { Undifferentiated } \\
\text { sarcoma }\end{array}$ & Not available \\
\hline 4 & 14.7, M & Absent & $\begin{array}{l}\text { Rt frontoparietal } \\
\text { lobe }\end{array}$ & $\begin{array}{l}\text { HA, It arm numbness, It hemipa- } \\
\text { resis (3) }\end{array}$ & $\begin{array}{l}\text { Rt frontoparietal hem- } \\
\text { orrhage } \times 2\end{array}$ & $\begin{array}{l}\text { Undifferentiated } \\
\text { sarcoma }\end{array}$ & Absent \\
\hline 5 & 11.1, F & Present & $\begin{array}{l}\text { Rt frontotempo- } \\
\text { ral lobe }\end{array}$ & Progressive HA \& lethargy (7) & $\begin{array}{l}\text { Rt MCA aneurysm } \\
\text { rupture } 1 \text { yr prior }\end{array}$ & MINST & Present \\
\hline 6 & $17.8, \mathrm{~F}$ & Absent & Rt frontal lobe & Acute onset severe $\mathrm{HA}(<1)$ & Rt frontal hemorrhage & $\begin{array}{l}\text { Undifferentiated } \\
\text { sarcoma }\end{array}$ & Not performed \\
\hline 7 & $12.5, \mathrm{M}$ & Absent & Rt parietal lobe & $\begin{array}{l}\text { Lt leg numbness (6 wks), acute } \\
\text { onset of HA, decreased LOC (1) }\end{array}$ & Rt parietal hemorrhage & $\begin{array}{l}\text { Rhabdomyosar- } \\
\text { coma }\end{array}$ & Not performed \\
\hline 8 & $5.8, F$ & Absent & Rt frontal lobe & N/V, lethargy, double vision (7) & - & $\begin{array}{l}\text { Pleomorphic } \\
\text { sarcoma }\end{array}$ & Absent \\
\hline
\end{tabular}

$\mathrm{HA}=$ headache; $\mathrm{LOC}=$ level of consciousness; N/V = nausea and vomiting.

* All tumors were nonmetastatic.

\section{Adjuvant Therapy}

The details of the adjuvant treatment modalities used are described in Table 2. All patients received focal radiation to the primary site at a median dose of 59.4 Gy (range 54-60 Gy) in 30 fractions with concomitant oral etoposide. The courses of ICE chemotherapy were administered in a sandwichlike manner prior to and following RT in 6 patients with a median number of 2 ICE cycles (range 2-4) before RT. Two patients underwent RT immediately after surgery and subsequently received adjuvant chemotherapy. The total number of ICE cycles delivered ranged from 6 to 8 (median 6). One patient, historically the oldest of this case series, received additional cycles of chemotherapy (idarubicin, vincristine, and cyclophosphamide) for a total of 10 cycles after surgery. Case 8 received consolidation therapy with sequential high-dose chemo- therapy (carboplatin, thiotepa) and autologous stem cell rescue because of unresectability of the tumor due to encasement of the MCA and persistent residual disease. The other 2 patients with initial incomplete resection (Cases 4 and 5) had a complete response to chemotherapy, and a second surgery planned prior to commencing RT was cancelled in both cases.

\section{Overall and Progression-Free Survival}

No patient relapsed or showed evidence of tumor progression. One patient (Case 4) died of a glioblastoma that developed within the area of the previous radiation field 7 years after his initial diagnosis. At a median follow-up of 4.9 years (range 1.9-17.9 years), 7 patients were alive without evidence of disease, providing a projected 5-year PFS and OS of $100 \%$ and $66.7 \%( \pm 27.2)$, respectively.
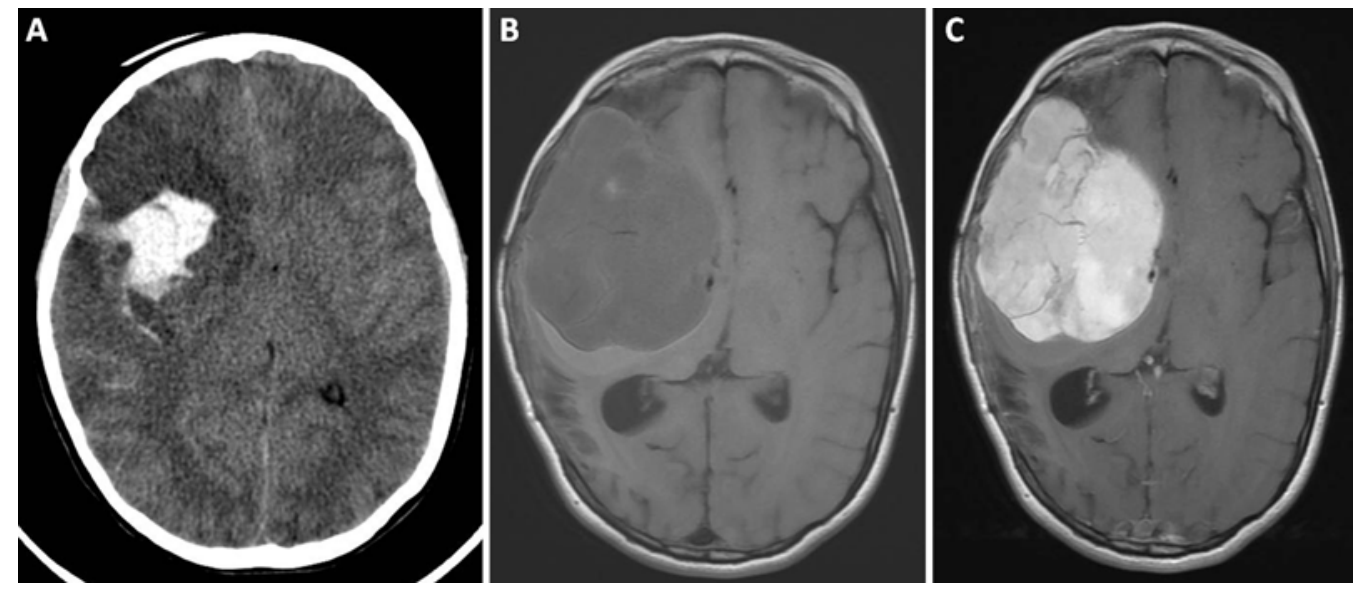

FIG. 1. Illustration of hemorrhagic presentation in Case 5. A: Diagnosis of right MCA aneurysm on axial CT scan without contrast. B and C: Diagnosis of MINST 1 year later on axial T1-weighted MRI without contrast (B) and axial T1-weighted FLAIR imaging with $\mathrm{Gd}(\mathrm{C})$. 
TABLE 2. Treatment description

\begin{tabular}{|c|c|c|c|c|c|c|}
\hline $\begin{array}{l}\text { Case } \\
\text { No. }\end{array}$ & $\begin{array}{c}\text { Age at Diagnosis } \\
\text { (yrs), Sex }\end{array}$ & $\begin{array}{l}\text { Extent of } \\
\text { Resection }\end{array}$ & Total No. of ICE Cycles & $\begin{array}{c}\text { No. of ICE Cycles } \\
\text { Before RT }\end{array}$ & $\begin{array}{l}\text { Radiation } \\
(\mathrm{Gy})^{*}\end{array}$ & $\begin{array}{c}\text { Status at Last FU } \\
\text { (time from diagnosis in yrs) }\end{array}$ \\
\hline 1 & $14.5, \mathrm{M}$ & GTR & 6 & 2 & Focal (60) & ANED (5.4) \\
\hline 2 & 7.7, M & GTR & 8 & 2 & Focal (60) & ANED (9.5) \\
\hline 3 & $6.5, \mathrm{~F}$ & GTR & $\begin{array}{l}\text { 6, }+4 \text { cycles of idarubicin, } \\
\text { VCR, CPM }\end{array}$ & 0 & Focal (54) & ANED (17.9) \\
\hline 4 & 14.7, M & NTR & 8 & 1 & Focal (60) & Dead of secondary glioblastoma (7.3) \\
\hline 5 & $11.1, \mathrm{~F}$ & PR & 6 & 4 & Focal (59.4) & $\operatorname{ANED}(3.4)$ \\
\hline 6 & $17.8, \mathrm{~F}$ & GTR & 6 & 2 & Focal (54) & ANED (2.1) \\
\hline 7 & $12.5, \mathrm{M}$ & GTR & 6 & 0 & Focal (54) & ANED (1.9) \\
\hline 8 & $5.8, F$ & STR† & $\begin{array}{l}6,+3 \text { cycles of high-dose } \mathrm{CB} \\
\text { thiotepa }\end{array}$ & 4 & Focal (59.4) & ANED (4.9) \\
\hline
\end{tabular}

ANED = alive with no evidence of disease $\mathrm{CB}=$ carboplatin; $\mathrm{CPM}=$ cyclophosphamide; $\mathrm{NTR}$ = near total resection; $\mathrm{PR}=$ partial resection; $\mathrm{VCR}=$ vincristine .

* All patients received oral etoposide during RT.

$\dagger$ Initial PR, STR on second-look surgery.

\section{Discussion}

This series of pediatric primary CNS sarcomas, although of limited number, is the first to report on a homogenous therapeutic approach for this particularly rare brain tumor. Two larger pediatric cohorts have been reported to date. The initial series from Toronto describing 16 patients encompassed a rather long study period (1960-1999) during which imaging techniques and histological criteria had evolved, making comparisons difficult. ${ }^{1}$ A more recent European retrospective database analysis identified 19 patients with intracranial sarcoma diagnosed between 1988 and $2009 .{ }^{2}$ In this series, all but 4 received adjuvant chemotherapy and RT. Different chemotherapy regimens were used during this time period. At a median follow-up of 5.8 years, $10(53 \%)$ of the 19 patients were alive, providing a 5-year PFS and OS of $47 \%( \pm 12 \%)$ and $74 \%( \pm 10 \%)$, respectively.

All of our patients had their tumors located in the right cerebral hemisphere, in contrast with previous adult and pediatric series in which tumor lateralization appeared evenly distributed. No clear explanation can be provided for this observation other than it may well be a random effect within a small cohort. This present series describes encouraging survival outcome data with maintained response rates on 8 patients treated with surgery and combined adjuvant focal radiation and ICE chemotherapy, with an estimated 5-year PFS of $100 \%$. The death of 1 patient was due to a secondary induced malignancy.

Given the rarity of these tumors, limited data are available on prognostic factors and best therapy. In an adult series, GTR followed by focal radiation appears to be the mainstay of treatment, with adjuvant chemotherapy being marginally used. ${ }^{12}$ In the pediatric series, surgical procedures also aim at maximal safe resection. Al-Gahtany et al. reported a mean survival of 6.2 years in the group with GTR compared with 3.4 years in cases of STR. ${ }^{1}$ In the German experience, patients with GTR had a better PFS at 5 years $(64 \% \pm 15 \%)$ than those with incomplete resection $(33 \% \pm 19 \%)$, but no statistical difference was found for OS at 5 years. These investigators suggested that complete tumor resection appears to be a prerequisite for longer survival. ${ }^{2}$ Similarly, for the majority of our patients, an upfront GTR was safely feasible (5 of 8), and 2 had a complete response of their residual disease to chemotherapy prior to the start of RT. The impact of extent of resection on outcome cannot be determined in this limited case series.

While the role of adjuvant chemotherapy in intracranial sarcoma remains unverified, most of the pediatric series focusing on intracranial sarcomas describe long-term survivors treated with adjuvant chemotherapy mostly in combination with RT, $2,4,13$ in contrast to adult series in which chemotherapy is marginally used. ${ }^{12}$ In the European series, ${ }^{2}$ only 1 of the long-term survivors (with a diagnosis of mesenchymal chondrosarcoma) was cured using adjuvant chemotherapy alone, while the remainder received both chemotherapy and RT. In our experience, complete response of the residual lesion to chemotherapy was observed in 2 of 3 patients prior to commencing RT, which suggests chemotherapy sensitivity.

Hemispheric locations appear to predominate for intracranial sarcomas. Although in the Al-Gahtany series, which includes 1 of our patients (Case 3), only 6 tumors $(37.5 \%)$ were located in the cerebral hemisphere, Benesch et al. ${ }^{2}$ described 13 patients $(68 \%)$ with hemispheric lesions, which is consistent with our rate of $8 / 13(61.5 \%)$. We chose to focus on the primary hemispheric sarcoma due to patients' specific clinical presentation, consisting of an acute symptomatic hemorrhagic manifestation at the time of diagnosis.

Spontaneous hemorrhage has previously been occasionally described as a presenting event in primary intracranial fibrosarcoma and rhabdomyosarcoma. ${ }^{4,10}$ In their clinicopathological study on hemorrhage in brain tumors, Kondziolka et al. reported evidence of macroscopic hemorrhage in 2 of their 3 intracranial sarcoma pathology samples. ${ }^{7}$ Of note, the acute onset of bleeding was the predominant symptom at presentation in 7 of our 8 patients. We could not find a correlative frequency rate of an associated hemorrhagic event at presentation from other published series. Our findings may suggest that the diagnosis of sarcoma, also rare in the brain, should be considered in the differential diagnosis in the event of hemispheric hemorrhage. It is unclear whether propensity of CNS sarcomas 
to spontaneously bleed could be related to vascular proliferation as observed in choroid plexus tumors. ${ }^{6,8}$ The cell of origin of these tumors may shed some light on their apparent increased risk of hemorrhage. McDonald et al. suggest that sarcomas arising from within the brain parenchyma presumably find their origin from mesenchymal cells associated with the vascular adventitia. ${ }^{10}$ Our description of 3 patients (Cases 1, 4, and 5) diagnosed with sarcoma after the second hemorrhagic event may further support this hypothesis, with the first episode constituting early manifestation of the neoplastic process within the vessel wall.

Patients affected by NF1 are known to be at higher risk of developing soft tissue sarcomas and CNS tumors than the general population. The CNS tumors in patients with NF1 are largely represented by benign optic pathway glioma and to a much lesser degree by glioblastoma and malignant intracerebral nerve sheath tumor (MINST), the latter classified within the sarcoma tumor group., ${ }^{5,14,16}$ While in the European series only 1 of the 19 patients had an NF1-related spindle cell sarcoma, our series had an overrepresentation of patients with NF1 (37.5\%). ${ }^{2}$ It is unclear whether our findings contrast with the current underreporting of this association or reflect a selection bias. In this context, it is important to note that none of our patients with infratentorial sarcoma had NF1. Furthermore, all 7 cases of MINST associated with NF1 reported to date were located in the cerebral hemispheres. ${ }^{3}$ Patients with NF1 are also known to be predisposed to several types of vascular malformations, notably moyamoya disease, arterial stenosis, and cerebral aneurysms. ${ }^{11,15}$ While there is no clear association between vascular malformation and malignancy, it is possible that a common mutation linked to the NF1 genotype could induce abnormal vascular development and/or alteration of the mechanisms of repair, which ultimately may predispose to malignant transformation of these altered vessels.

\section{Conclusions}

Primary intracranial sarcomas are rare malignant CNS tumors. In our series, intracranial sarcomas located in the cerebral hemisphere were associated with intratumoral hemorrhage at the time of presentation and with an overrepresentation of patients with NF1. Therapeutic management consisting of resection, ICE chemotherapy, and focal radiation resulted in an encouraging survival rate.

\section{References}

1. Al-Gahtany M, Shroff M, Bouffet E, Dirks P, Drake J, Humphreys R, et al: Primary central nervous system sarcomas in children: clinical, radiological, and pathological features. Childs Nerv Syst 19:808-817, 2003 (Erratum in Childs Nerv Syst 20:371, 2004)

2. Benesch M, von Bueren AO, Dantonello T, von Hoff K, Pietsch T, Leuschner I, et al: Primary intracranial soft tissue sarcoma in children and adolescents: a cooperative analysis of the European CWS and HIT study groups. J Neurooncol 111:337-345, 2013

3. Ellis MJ, Cheshier S, Sharma S, Armstrong D, Hawkins C, Bouffet E, et al: Intracerebral malignant peripheral nerve sheath tumor in a child with neurofibromatosis Type 1 and middle cerebral artery aneurysm treated with endovascular coil embolization. J Neurosurg Pediatr 8:346-352, 2011

4. Guilcher GM, Hendson G, Goddard K, Steinbok P, Bond M:
Successful treatment of a child with a primary intracranial rhabdomyosarcoma with chemotherapy and radiation therapy. J Neurooncol 86:79-82, 2008

5. Huttner AJ, Kieran MW, Yao X, Cruz L, Ladner J, Quayle $\mathrm{K}$, et al: Clinicopathologic study of glioblastoma in children with neurofibromatosis type 1. Pediatr Blood Cancer 54:890-896, 2010

6. Jaiswal S, Vij M, Mehrotra A, Kumar B, Nair A, Jaiswal AK, et al: Choroid plexus tumors: A clinico-pathological and neuro-radiological study of 23 cases. Asian J Neurosurg 8:29-35, 2013

7. Kondziolka D, Bernstein M, Resch L, Tator CH, Fleming JF, Vanderlinden RG, et al: Significance of hemorrhage into brain tumors: clinicopathological study. J Neurosurg 67:852-857, 1987

8. Lafay-Cousin L, Mabbott DJ, Halliday W, Taylor MD, Tabori U, Kamaly-Asl ID, et al: Use of ifosfamide, carboplatin, and etoposide chemotherapy in choroid plexus carcinoma. J Neurosurg Pediatr 5:615-621, 2010

9. Louis DN, Ohgaki H, Wiestler OD, Cavenee WK, Burger PC, Jouvet A, et al: The 2007 WHO classification of tumours of the central nervous system. Acta Neuropathol 114:97-109, 2007

10. McDonald P, Guha A, Provias J: Primary intracranial fibrosarcoma with intratumoral hemorrhage: neuropathological diagnosis with review of the literature. J Neurooncol 35:133-139, 1997

11. Oderich GS, Sullivan TM, Bower TC, Gloviczki P, Miller DV, Babovic-Vuksanovic D, et al: Vascular abnormalities in patients with neurofibromatosis syndrome type I: clinical spectrum, management, and results. J Vasc Surg 46:475484, 2007

12. Oliveira AM, Scheithauer BW, Salomao DR, Parisi JE, Burger PC, Nascimento AG: Primary sarcomas of the brain and spinal cord: a study of 18 cases. Am J Surg Pathol 26:1056-1063, 2002

13. Olson JJ, Menezes AH, Godersky JC, Lobosky JM, Hart M: Primary intracranial rhabdomyosarcoma. Neurosurgery 17:25-34, 1985

14. Oztanir N, Emmez H, Aytar MH, Dogan M, Kaymaz M, Baykaner MK: Malignant intracerebral giant nerve sheath tumor in a 14-month-old girl with neurofibromatosis type 1 : a case report. Childs Nerv Syst 25:253-256, 2009

15. Rosser TL, Vezina G, Packer RJ: Cerebrovascular abnormalities in a population of children with neurofibromatosis type 1. Neurology 64:553-555, 2005

16. Ueda R, Saito R, Horiguchi T, Nakamura Y, Ichikizaki K: Malignant peripheral nerve sheath tumor in the anterior skull base associated with neurofibromatosis type 1-case report. Neurol Med Chir (Tokyo) 44:38-42, 2004

\section{Disclosures}

The authors report no conflict of interest concerning the materials or methods used in this study or the findings specified in this paper.

\section{Author Contributions}

Conception and design: Bartels. Acquisition of data: LafayCousin, Lindzon. Analysis and interpretation of data: LafayCousin. Drafting the article: Lafay-Cousin, Lindzon. Critically revising the article: Bartels, Taylor, Bouffet. Reviewed submitted version of manuscript: Bartels, Lafay-Cousin, Taylor, Hader, Hawkins, Nordal, Laperriere, Laughlin, Bouffet. Statistical analysis: Lafay-Cousin. Study supervision: Bartels.

\section{Correspondence}

Ute Bartels, The Hospital for Sick Children, Division of Haematology/Oncology, 555 University Ave., Toronto, ON M5G 1X8, Canada. email: ute.bartels@sickkids.ca. 